\title{
Large amount of settlement brought by the river
}

\author{
Dongfang Yang ${ }^{1,2,{ }^{*}}$, Haixia $\mathrm{Li}^{1}$, Qi Wang ${ }^{1}$, Hong Zhu ${ }^{1}$, and Weifeng Ling ${ }^{1}$ \\ ${ }^{1}$ Accountancy School, Xijing University, Xi'an 710123, China, \\ ${ }^{2}$ North China Sea Environmental Monitoring Center, SOA, Qingdao 266033, China,
}

\begin{abstract}
Utilizing the survey dataset of $\mathrm{Pb}$ in waters from south of bay mouth to southeast of bay in October 1992, and applying the horizontal and vertical change models of matter content put forward by authors, we would calculate the horizontal loss amount, vertical diluted amount and vertical sediment amount of $\mathrm{Pb}$ in surface and bottom layers and set up the model diagram on the $\mathrm{Pb}$ content horizontal and vertical changes. The research results unveiled that in October, the absolutely horizontal loss amount of $\mathrm{Pb}$

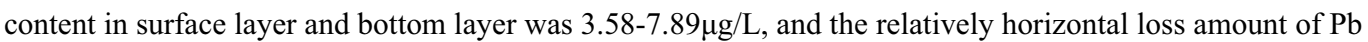
content in surface layer and bottom layer was $27.01-51.30 \%$. In the southern waters of bay mouth, the absolutely vertical sediment amount of $\mathrm{Pb}$ was $2.13 \mu \mathrm{g} / \mathrm{L}$, and the relatively vertical sediment amount was $13.84 \%$. In the southeastern waters of the bay, $\mathrm{Pb}$ content in the surface layer and bottom layer had an absolutely vertical diluted amount of $6.61 \mu \mathrm{g} / \mathrm{L}$ and a relatively vertical diluted amount of $22.54 \%$. In October, in the surface waters, after the main sea current brought high $\mathrm{Pb}$ content to the southern waters of the bay mouth, the $\mathrm{Pb}$ content began to settle to the seabed in large quantities, leading to a horizontal loss amount of almost one third $27.01 \%$ of the $\mathrm{Pb}$ content on surface when the current entered the bay. $\mathrm{Pb}$ content in the bottom layer of the seabed also reduced greatly by $51.30 \%$, which was more than half. It revealed that $\mathrm{Pb}$ content in the surface layer could settle to the bottom rapidly and continuously when the current entered the bay, causing a large loss amount of $\mathrm{Pb}$ content in the surface layer. At the same time, the $\mathrm{Pb}$ content on the bottom was largely buried in the seabed, causing a lot of losses. In October, in the process of vertical migration, the vertical sediment amount of $\mathrm{Pb}$ in the surface and bottom layers $13.84 \%$ was shifted to the vertical diluted amount of $\mathrm{Pb}$ in the surface and bottom layers $22.54 \%$ before and after the main sea current entered the bay. The high $\mathrm{Pb}$ content transported by the main sea current had a large amount of settlement in the southern waters of the bay mouth and accumulated in the seabed. However, when the current reached the bay with $\mathrm{Pb}$ content, there was also a large amount of settlement in the southeastern part of the bay, but no accumulation in the seabed.
\end{abstract}

\section{Introduction}

In the surface waters of Jiaozhou Bay, the $\mathrm{Pb}$ content increased because of the high $\mathrm{Pb}$ content carried by the main sea current from the outside to the inside of bay through the bay mouth. When the current left the bay, $\mathrm{Pb}$ content passed through the water from the surface and settled to the seabed with its own horizontal and vertical migration, [1-8]. By applying the horizontal change model and the vertical change model of matter content, and analyzing the survey dataset on $\mathrm{Pb}$ content of the Jiaozhou Bay water in October 1992, the authors got the horizontal migration process and vertical subsidence process of $\mathrm{Pb}$ content when the current just entered Jiaozhou Bay and illustrating that $\mathrm{Pb}$ content derived from main currents migrated from the surface of one water body to that of another and then settled to the bottom of the sea, to provide scientific basis for the study of the $\mathrm{Pb}$ content's vertical settlement and horizontal migration in surface and bottom waters.

\section{The Waters and Methods of the Survey}

2.1 Natural Environment of Jiaozhou Bay. Jiaozhou Bay is between $120^{\circ} 04^{\prime}-120^{\circ} 23^{\prime} \mathrm{E}, 35^{\circ} 58^{\prime}$ $36^{\circ} 18^{\prime} \mathrm{N}$, showing a semi-closed bay with the area about $446 \mathrm{~km}^{2}$ and the average water depth about $7 \mathrm{~m}$. Moreover, the tunnel of the bay into the Yellow Sea presented the line between Tuan Island and XueJia Island. A dozen rivers into Jiaozhou Bay brought a large amount of the runoff and sediment concentration to the bay, such as Dagu River, Yang River, Haibo River, Licun River and Loushan River around Jiaozhou bay and in Qingdao urban area.

2.2 Materials and Methods. By investigation in October 1992, the North China Sea Environmental Monitoring Center provided the survey dataset of $\mathrm{Pb}$ in Jiaozhou Bay. By choosing the two stations: Stations 52 and 60 in the waters of Jiaozhou Bay, we got the water

"Corresponding author:*dfyang @shou.edu.cn 
samples from the stations (Figure 1). In October 1992, we got the different water samples by utilizing the different depth of water $(>10 \mathrm{~m}$, got from the surface and bottom layers ; $<10 \mathrm{~m}$, only from the surface layer) for investigation. We collected the $\mathrm{Pb}$ survey dataset of Jiaozhou Bay water body by relying on the national standard method, included in the Specification for Marine Monitoring (1991) [9].

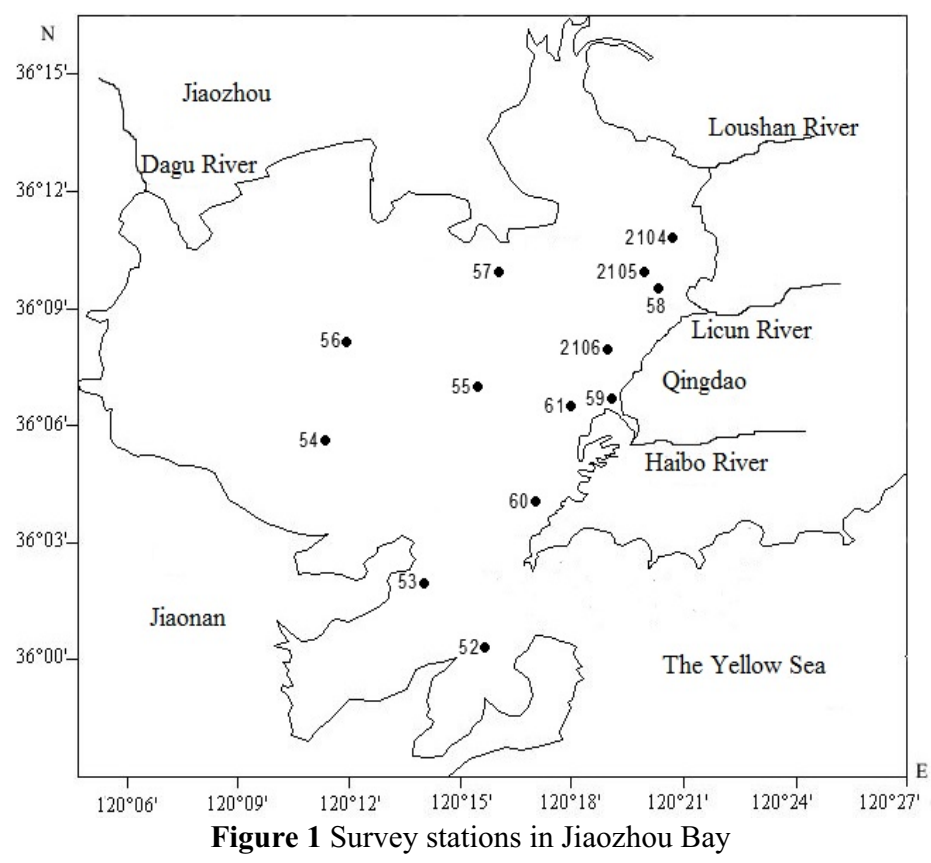

\section{Results}

3.1 Waters from South of Bay Mouth to Southeast of the Bay. The main sea current carried high $\mathrm{Pb}$ content through the bay mouth into Jiaozhou Bay. It reached the southern part of the bay mouth then arrived at the southeastern waters of the bay.

Station 52 lies in the southern waters of bay mouth, and Station 60 in the southeastern waters of Jiaozhou Bay. In surface waters in October, the main sea current flowed into Jiaozhou Bay and passed the southern waters of the bay mouth. First, it reached station 52 where the $\mathrm{Pb}$ content was $13.25 \mu \mathrm{g} / \mathrm{L}$. Then the current arrived at station 60 , with a $\mathrm{Pb}$ content of $9.67 \mu \mathrm{g} / \mathrm{L}$. Meanwhile, in the bottom waters, through the southern waters of the bay mouth, the current flowed and went into the bay. The main sea current first reached station 52 where the $\mathrm{Pb}$ content was the maximum value of $15.38 \mu \mathrm{g} / \mathrm{L}$, and then it at station 60 with the $\mathrm{Pb}$ content of $7.49 \mu \mathrm{g} / \mathrm{L}$.

\subsection{Definition of Horizontal Substance Content} Change. In Jiaozhou Bay, while the current transferred the matter content, the matter content decreased continuously with the current moving. the authors presented the definition and formula, then and calculated horizontal loss amount, vertical diluted amount and vertical sediment amount of matter content. Moreover, the authors further divided horizontal loss amount into absolutely horizontal loss amount and relatively horizontal loss amount. In the same way, the authors divided the vertical diluted amount into absolutely vertical diluted and sediment amount and relatively vertical diluted and sediment amount.
3.3 Formula for the Change of Horizontal Substance Content. In the surface waters from south of the bay mouth to southeast of Jiaozhou Bay, it is assumed that the content of matter $(\mathrm{M})$ in the south of the bay mouth is A and that in the southeast of the bay is B.

From the southern waters of the bay mouth to the southeastern waters of the bay, the absolutely horizontal loss amount is regarded as $\mathrm{D}>0$. The relatively horizontal loss amount is regarded as $\mathrm{E}$. When $\mathrm{D}<0$, absolutely horizontal loss amount of matter content in the waters from southeast of the bay to south of the bay mouth is $-\mathrm{D}>0$.

$$
\mathrm{D}=\mathrm{A}-\mathrm{B}, \mathrm{E}=|\mathrm{A}-\mathrm{B}| / \max (\mathrm{A}, \mathrm{B})
$$

In a similar way, in the bottom waters from south of the bay mouth to southeast of Jiaozhou Bay, it is assumed that the material content in the south of bay mouth is a and that in the southeast of the bay is b.

From the southern waters of the bay mouth to the southeastern waters of the bay, the absolutely horizontal loss amount is $\mathrm{d}>0$, the relatively horizontal loss amount is e. When $\mathrm{d}<0$, the absolutely horizontal loss amount in the waters from southeast of the bay to south of the bay mouth is regarded as $-\mathrm{d}<0$.

$$
\mathrm{d}=\mathrm{a}-\mathrm{b}, \mathrm{e}=|\mathrm{a}-\mathrm{b}| / \max (\mathrm{a}, \mathrm{b})
$$

\subsection{Formula of Vertical Substance Content} Change. In the waters from south of the bay mouth to southeast of Jiaozhou Bay, it is assumed that in the south of the bay mouth, the matter content of surface water is regarded as $\mathrm{A}$, that of bottom water is regarded as a, and the station of the water area is regarded as n. From the surface waters to the bottom waters, the absolutely vertical diluted amount of material content is regarded as Vna $>0$. The relatively vertical diluted amount of substance content is regarded as $\mathrm{Vnr}$. When $\mathrm{Vna}<0$, the 
absolutely vertical diluted amount of material content is regarded as $-\mathrm{Vna}>0$ and the relatively vertical diluted amount of substance content is regarded as $\mathrm{Vnr}$.

$$
\mathrm{Vna}=\mathrm{A}-\mathrm{a}, \mathrm{Vnr}=|\mathrm{A}-\mathrm{a}| / \max (\mathrm{A}, \mathrm{a})
$$

\subsection{Horizontal Loss Amount of Surface Layer} and Bottom Layer. Provided that movement from station 52 in the southern waters of the bay mouth to station 60 in the southeastern waters was compared to that from $\mathrm{A}$ to $\mathrm{B}$ and $\mathrm{Pb}$ content is the main part of matter content. Then the horizontal change of $\mathrm{Pb}$ content unveiled the horizontal loss amount of $\mathrm{Pb}$ content in the surface layer and the bottom layer.

In October, in the surface waters of Jiaozhou Bay from the south of the bay mouth to the southeast of the bay, the $\mathrm{Pb}$ content changed greatly when the current left the bay. The formula (1) by calculation gave the horizontal loss amount of $\mathrm{Pb}$ content in the surface waters (Table 1).

Table 1 Horizontal loss amount of $\mathrm{Pb}$ content in the surface

\begin{tabular}{|c|c|c|c|}
\multicolumn{4}{|c|}{ layer } \\
\hline From A to B & D & E & E \\
\hline October & 3.58 & 0.2701 & $27.01 \%$ \\
\hline
\end{tabular}

At the same time, in the bottom water of Jiaozhou Bay from station 52 to Station 60 , the $\mathrm{Pb}$ content also changed greatly when the current left the bay. With formula (2), the horizontal loss amount of $\mathrm{Pb}$ in the bottom water was calculated (Table 2).

Table 2 Horizontal loss amount of $\mathrm{Pb}$ content in the bottom

\begin{tabular}{|c|c|c|c|}
\multicolumn{4}{|c|}{ layer } \\
\hline From A to B & d & e & e \\
\hline October & 7.89 & 0.5130 & $51.30 \%$ \\
\hline
\end{tabular}

3.6 Vertical Diluted and Sediment Amounts. The matter content in this paper was regarded as the $\mathrm{Pb}$ content. The vertical variation of $\mathrm{Pb}$ content disclosed the vertical diluted and sediment amounts of $\mathrm{Pb}$ in surface layer and bottom layer.

In October, in the waters from the south of the bay mouth to the southeast of Jiaozhou Bay, $\mathrm{Pb}$ content in both surface and bottom waters changed greatly. The formula (3) showed vertical diluted and sediment amounts of $\mathrm{Pb}$ content in the bottom layer (Table 3 ).

Table 3 Vertical diluted and sediment amounts of $\mathrm{Pb}$ content in the surface and bottom layer

\begin{tabular}{|c|c|c|c|c|}
\hline time & water & Vna & Vnr & Vnr \\
\hline October & $\begin{array}{c}\text { waters of southern } \\
\text { bay mouth }\end{array}$ & -2.13 & 0.1384 & $13.84 \%$ \\
\cline { 2 - 5 } & $\begin{array}{c}\text { waters of } \\
\text { southeastern bay }\end{array}$ & 2.18 & 0.2254 & $22.54 \%$ \\
\hline
\end{tabular}

\section{Discuss}

\subsection{Changes in the Substance Content of the} Current Track in the Bay. In the waters of Jiaozhou Bay, $\mathrm{Pb}$ content $13.25 \mu \mathrm{g} / \mathrm{L}$ was derived from the main sea current in October. The main sea current carried high $\mathrm{Pb}$ content into Jiaozhou Bay and surrounded the nearshore waters of the bay and then left (Figure 2). The current passed through the water body in the south of the bay mouth (station 52) and reached the water body in the southeast of the bay (station 60). Using the horizontal matter content change model and vertical matter content change model quantitatively determined the horizontal and vertical migration of $\mathrm{Pb}$ content in the waters from south of the bay mouth to southeast of the bay.

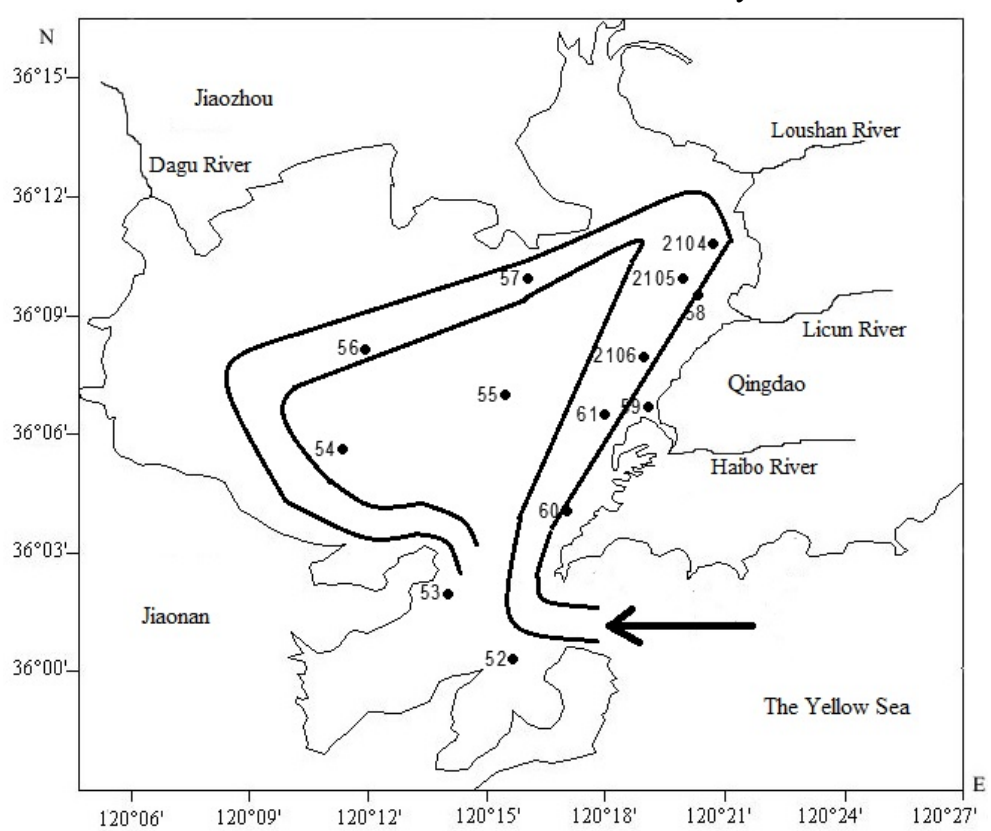

Figure 2 The flow path of the main sea current with a high content of $\mathrm{Pb}$ in Jiaozhou Bay $(\mu \mathrm{g} / \mathrm{L})$

4.2 Horizontal and Vertical Variations of $\mathrm{Pb}$ Content. $\mathrm{Pb}$ content $13.25 \mu \mathrm{g} / \mathrm{L}$ in the waters from the south of the bay mouth to southeastern Jiaozhou Bay in October was derived from main sea current transport. In the waters of Jiaozhou Bay, Pb content decreased along the gradient under the action of tides and currents.

However, when the current reached the south of the bay mouth, $\mathrm{Pb}$ content in surface water decreased significantly. At the same time, $\mathrm{Pb}$ content in the bottom 
water decreased enormously. It indicates that from the south of the bay mouth to the southeast of the bay especially when the current entered the bay, the $\mathrm{Pb}$ content of surface water had a lot of settlement.

During the current movement, $\mathrm{Pb}$ content in surface layer with the absolutely horizontal loss amount was $3.58 \mu \mathrm{g} / \mathrm{L}$ and bottom layer with the absolutely horizontal loss amount was $7.89 \mu \mathrm{g} / \mathrm{L}$ decreased significantly. It reveals that some of the high $\mathrm{Pb}$ content transported to Jiaozhou Bay by the main sea current was left on the bottom when the current got into the bay.

In October, from the waters in the south of the bay mouth to the waters in the southeast of the bay, the horizontal loss amount of $\mathrm{Pb}$ content in the surface layer reached $27.01 \%$ when the current entered the bay. Similarly, the horizontal loss amount of $\mathrm{Pb}$ content in the bottom layer reached a high value of $51.30 \%$. (Figure 3 ). In southern waters of the bay mouth, the vertical sediment amount of $\mathrm{Pb}$ content in the surface layer and bottom layer was relatively low, reaching $13.84 \%$. While in southeastern waters of the bay, the vertical diluted amount of $\mathrm{Pb}$ content $22.54 \%$ in the surface layer and bottom layer was relatively low (Figure 3 ).

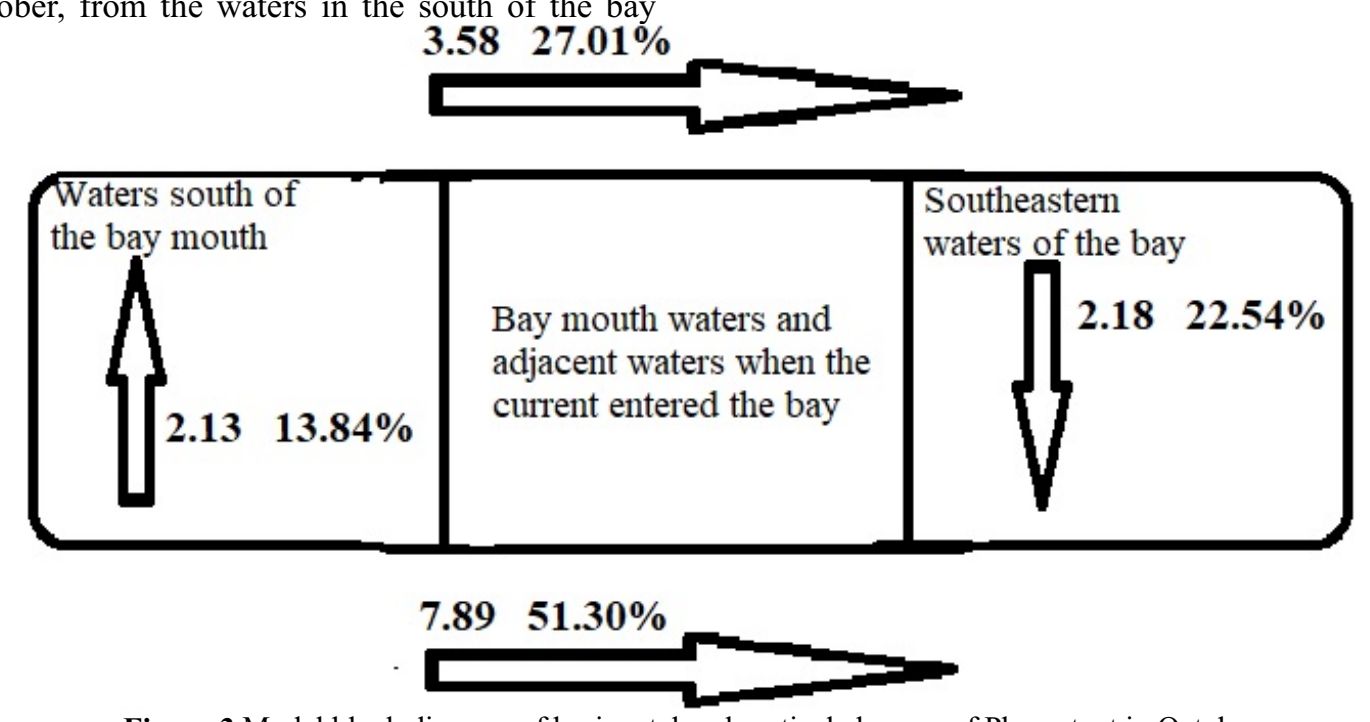

Figure 3 Model block diagram of horizontal and vertical changes of $\mathrm{Pb}$ content in October

In conclusion, in October, the absolutely horizontal loss amount of $\mathrm{Pb}$ in the surface layer and the bottom layer was $3.58-7.89 \mu \mathrm{g} / \mathrm{L}$ and the relatively horizontal loss amount was $27.01-51.30 \%$. In the southern waters of the bay mouth, the $\mathrm{Pb}$ content in the surface layer and the bottom layer showed an absolutely vertical sediment amount of $2.13 \mu \mathrm{g} / \mathrm{L}$ and a relatively vertical sediment amount of $13.84 \%$. Meantime, in the southeastern waters of the bay, the $\mathrm{Pb}$ content in the bottom layer had an absolute vertical diluted amount of $6.61 \mu \mathrm{g} / \mathrm{L}$ and a relative vertical diluted amount of $22.54 \%$.

4.3 Horizontal Loss Amount. In October, the horizontal loss amount of $\mathrm{Pb}$ content in the surface layer $27.01 \%$ reached a relatively high level (Table 1 ), nearly a third, from the south of the bay mouth to the southeast of the bay. It indicates that when the current got into the bay, a large amount of $\mathrm{Pb}$ content in the surface layer rapidly and continuously deposited to the bottom of Jiaozhou Bay.

Meanwhile, from the waters in the south of the bay mouth tothe waters in the southeast of the bay, the horizontal loss amount of $\mathrm{Pb}$ content in the bottom layer $51.30 \%$ reached a relatively high level too (Table 2 ). The horizontal loss amount of more than half indicates that during the horizontal migration of $\mathrm{Pb}$ content in the bottom layer, $\mathrm{Pb}$ content in the surface layer rapidly and continuously sank to the seabed, buried beneath the ocean in the bottom layer.

Judging from these, in the surface water in October, the $\mathrm{Pb}$ content in the surface layer of the bay deposited to the bottom of the bay in large quantities after the main sea current came to the waters south of the bay mouth with high $\mathrm{Pb}$ content and entered the bay. As a result, during the horizontal migration of $\mathrm{Pb}$ content in the surface and bottom layers, the absolutely horizontal loss amount of $\mathrm{Pb}$ content in the surface layer reached $27.01 \%$ - almost one third. What's more, the $\mathrm{Pb}$ content at the bottom of the sea floor decreased greatly, reaching more than half $51.30 \%$. It reveals that the high $\mathrm{Pb}$ content in the surface layer could rapidly and continuously settle to the seabed when the current got into Jiaozhou Bay, which caused a large amount of $\mathrm{Pb}$ content to be lost in the surface layer. At the same time, the $\mathrm{Pb}$ content in the bottom layer was largely buried in the seabed, resulting in a large loss amount of $\mathrm{Pb}$ content in the bottom layer.

4.4 Vertical Loss Amount. In Jiaozhou Bay, in October, the high $\mathrm{Pb}$ content transported by the main sea current first reached the waters south of the bay mouth where the vertical sediment amount of $\mathrm{Pb}$ content in the surface layer and bottom layer reached a low value of $13.84 \%$. Then the main sea current entered the inner waters and reached the waters in the southeast of the bay where the vertical diluted amount of $\mathrm{Pb}$ content in the surface and bottom reached a low value of $22.54 \%$. It reveals that when the current entered the southern part of the bay mouth, the $\mathrm{Pb}$ content in the surface layer could settle to the seabed rapidly and continuously, leaving 
little sediment amount on the bottom. And when the current got into the southeastern waters of the bay, part of $\mathrm{Pb}$ content in the surface layer settles to the seabed, but there is no accumulation in the seabed. To put it in a nutshell, in October, in the vertical migration process, the vertical sediment amount of $\mathrm{Pb}$ content in surface and bottom layers $13.84 \%$ was changed to the vertical diluted amount of $\mathrm{Pb}$ content in surface and bottom layers $22.54 \%$ before and after the main sea current entered the bay. The high $\mathrm{Pb}$ content transported by the main sea current had a large amount of settlement in the southern waters of the bay mouth and accumulated in the seabed. However, when the current reached the bay with $\mathrm{Pb}$ content, there was also a large amount of settlement in the southeastern part of the bay, but no sediment in the seabed.

\section{Conclusion}

By utilizing the horizontal substance content change model and vertical substance content change model, the authors got the horizontal loss amount, vertical diluted amount and vertical sediment amount of $\mathrm{Pb}$ in the surface layer and bottom layer and determined the model block diagram of the horizontal and vertical variation of $\mathrm{Pb}$ content. In October, the absolutely horizontal loss amount of $\mathrm{Pb}$ content in surface layer and bottom layer was $3.58-7.89 \mu \mathrm{g} / \mathrm{L}$ and the relatively horizontal loss amount was $27.01-51.30 \%$. In the southern waters of the bay mouth, the absolutely vertical sediment amount of $\mathrm{Pb}$ content both in surface layer and bottom layer was $2.13 \mu \mathrm{g} / \mathrm{L}$, and the relatively vertical sediment amount was $13.84 \%$. While in the waters southeast of the bay, the absolutely vertical diluted amount of $\mathrm{Pb}$ in the surface and bottom was $6.61 \mu \mathrm{g} / \mathrm{L}$, and the relative vertical diluted amount was $22.54 \%$.

At the same time, during the horizontal migration of $\mathrm{Pb}$ content, from the southern part of the bay mouth to the southeastern part of the bay, a large amount of $\mathrm{Pb}$ content in the surface layer settled to the seabed as the current entered the bay. The loss amount of $\mathrm{Pb}$ content in the surface layer reached almost $30 \%$. It discloses that the $\mathrm{Pb}$ content in the surface layer could rapidly and continuously settle to the seabed, left at the bottom of the bay mouth.In the horizontal migration process of $\mathrm{Pb}$ bottom layer content, there was a more than half of $51.30 \%$ reduction. Thus, the high $\mathrm{Pb}$ content in the surface layer can settle to the seabed rapidly and continuously, more than half $-51.30 \%$ of which was buried by the sea floor.

In the meantime, in the process of vertical migration, as ocean currents entered the waters south of the bay mouth, The $\mathrm{Pb}$ content in the surface layer could settle to the seabed rapidly and continuously, and there was a small sediment amount in the seabed, which was $13.84 \%$. When the current got into the southeastern waters of the bay, the vertical diluted amount of $\mathrm{Pb}$ content on the surface and bottom reached a low value of $22.54 \%$. Some $\mathrm{Pb}$ content in the surface layer settled on the seabed, but there was no sediment there.

\section{References}

1. Dongfang Yang, Danfeng Yang, Sixi Zhu, Ming Wang, Mingzhong Long. The spreading process of $\mathrm{Pb}$ in Jiaozhou Bay [J]. Advances in Engineering Research. 2016, 1921-1926.

2. Dongfang Yang, Sixi Zhu, Ming Wang, Xiuqin Yang, Fengyou Wang. High sedimentation rate of $\mathrm{Pb}$ in the bay mouth of Jiaozhou Bay [J]. Advances in Engineering Research. 2016, Vol.65: 293-297.

3. Dongfang Yang, Sixi Zhu, Danfeng Yang, Zhikang Wang, Xiuqin Yang. Vertical migration and sedimentation of $\mathrm{Pb}$ in Jiaozhou Bay [J]. Advances in Engineering Research. 2016, Vol.65: 303-307.

4. Dongfang Yang, Xiancheng Qu,Yu Chen, Shubo Fang, Yinjiang Zhang. Annual change of $\mathrm{Pb}$ contents in Jiaozhou Bay during 1979-1983 [J]. Advances in Engineering Research. 2016, 84: 848-851.

5. Dongfang Yang, Yu Chen, Shubo Fang and Yinjiang Zhang, Xiancheng Qu. Seasonal variations of $\mathrm{Pb}$ contents and pollution levels in Jiaozhou Bay in the early stage of reform and opening-up [J]. Advances in Engineering Research. 2016, 84: 857-860.

6. Dongfang Yang, Yu Chen, Xiancheng Qu, Danfeng Yang and Yinjiang Zhang. Seasonal-vertical variations of $\mathrm{Pb}$ and their mechanisms in marine bay[J]. Advances in Engineering Research. 2016, 88: 1970-1973.

7. Dongfang Yang, Yinjiang Zhang, Xiancheng Qu, Danfeng Yang and Yu Chen. The land-ocean transfer process of $\mathrm{Pb}[\mathrm{J}]$. Advances in Engineering Research. 2016, 88: 1974-1977.

8. Dongfang Yang, Hongmin Suo, Sixi Zhu, Yi Wang and Mingzhong Long. High sedimentation rate of $\mathrm{Pb}$ and the mechanism in Jiaozhou Bay [J]. Advances in Engineering Research. 2016, 83: 479-483.

9. State Oceanic Administration. The Specification for Marine Monitoring [Z]. Beijing: China Ocean Press, 1991. 